\title{
AS AMBIGUIDADES NOS ATOS PERFORMATIVOS DOS RAPAZES NEGROS ESTUDANTES: POSSIBILIDADES PARA UMA EDUCAÇÃO LIBERTADORA
}

\author{
Suely Aldir Messeder ${ }^{1}$ \\ Elisete Santana da Cruz França ${ }^{2}$ \\ Maria Nazaré Mota de Lima ${ }^{3}$
}

\begin{abstract}
Resumo: O artigo escrito por três mulheres pesquisadoras, educadoras e negras buscou compreender como os jovens negros reinterpretam as brincadeiras infantis na construção de suas masculinidades, mediante a reconstrução das narrativas destes rapazes, no âmbito de um grupo focal desenvolvido no contexto escolar soteropolitano. Na analise destas narrativas foi possível identificar que a brincadeira de luta ou a briga é mais praticada por eles, embora tivessem elencado o pega-pega, futebol, rasteira, handebol, esconde-esconde, os desenhos animados animes, papai e mamãe. Na interpretação sobre a luta reportou-se a outras dimensões que se coloca na ambiguidade entre o natural e cultural (aprendizado), daí a possibilidade de apostar nas zonas dos interstícios, enfrentando a moralidade da maioria, tendo como conteúdo a ser trabalhado as diversidades das próprias vivências. Embora, o foco de análise centra-se nas narrativas destas vivências, foi considerado as lógicas de opressão da desigualdade de classe, do racismo, do sexismo e da heteronormatividade estruturadas e estruturantes destas vivências.
\end{abstract}

Palavras-chave: Atos performativos; Contexto escolar; Gênero; Masculinidades.

\section{THE AMBIGUITIES IN PERFORMATIVE ACTS OF BLACK BOYS STUDENTS: POSSIBILITIES FOR A LIBERATING EDUCATION}

\begin{abstract}
The article, which was written by three female researchers, educators and blacks, sought to comprehend how young blacks reinterpret children's plays in the construction of their masculinities upon the reconstruction of the narratives of these boys, within the ambit of a focal group developed in the soteropolitano school context. In the analysis of these narratives it was possible to identify that the play of fight or struggle is more practiced by them, although they had listed the run and catch, football, sweep kick, handball, hide and seek, animes cartoons, mommies and daddies play. In the interpretation about the fight, other dimensions were referred which are placed in the ambiguity between the natural and cultural (learning). Thence the possibility of waging in the interstices zones, facing the morality of the majority, having as content to be worked the diversities of the own experiences. Although the focus of analysis is centered in the narratives of these experiences, the logics of oppression of class inequality, racism, sexism and the structured and structuring heteronormativity of such experiences were considered.
\end{abstract}

Keywords: Performative acts; School context; Genre; Masculinities.

1 É professora adjunta da Universidade do Estado da Bahia - UNEB e coordenadora do Doutorado Multiinstitucional e Multidisciplinar em Difusão do Conhecimento e professora permanente do Programa de PósGraduação Mestrado em Crítica Cultural do Campus II - Alagoinhas. Seus interesses em ensino, pesquisa e extensão estão nas áreas de sexualidades, homocultura, masculinidades, relações de gênero, corpo, relações étnico-raciais, baianidade, fluxos migratórios, antropologia urbana, teoria cognitivista, teoria feminista e teoria queer. Email: suelymesseder@gmail.com

2 Doutoranda do Programa Multi-institucional e Multidisciplinar em Difusão do Conhecimento - UFBA. Atualmente é professora da Fundação Visconde de Cairu, Diretora da Educação e suas Modalidades da Secretaria da Educação do Estado da Bahia. Email: zetefranca26@gmail.com

${ }^{3}$ Professora adjunta da Universidade do Estado da Bahia, com atuação no Programa de Pós-graduação em Crítica Cultural - PÓS-CRÍTICA. Pesquisadora associada da Universidade Estadual de Campinas, é colaboradora do ICEAFRO: Educação para a Igualdade Racial e de Gênero. Tem experiência na área de Letras, com ênfase em Língua Portuguesa, voltada para os seguintes temas: formação de professores/as, identidade étnico-racial e de gênero, literatura e letramento. Email: librianar@gmail.com

Momento: diálogos em educação, E-ISSN 2316-3100, v. 26, n. 1, p. 191-210, jan.jun. 2017 


\section{INTRODUÇÃO}

"A violência nas crianças vem de tempos passados... Porque antigamente as pessoas já nasciam lutando pra sobreviver. E esse sentimento vai passando de pessoa pra pessoa. Você pode ver você dá um brinquedo pra uma criança, a criança vai... ou jogar longe, ou ela vai abrir pra ver o que é que tem dentro ou ela vai simplesmente quebrar porque é assim, ela sente prazer nisso. Então, isso não é cortado na infância e... não é apresentado um amor, digamos assim, não é apresentada uma forma real do que realmente aconteceria se ela não quebrasse. Só apresentam "se você quebrar você vai apanhar", ou "se você quebrar você vai receber um carão". E não "se você quebrar você não vai ter mais depois". "Se você quebrar não vamos ter como te dar depois". E vem um pouco disso também, mostrando superioridade... e é isso" (Ângelo, 2016) ${ }^{4}$ [sic]

Interessante como o conteúdo deste discurso, versando sobre "brincadeira na infância", nos mobiliza, como pesquisadoras e educadoras, a refletir sobre como as vivências infantis são reinterpretadas, através da reconstrução notoriamente autobiográfica do nosso jovem estudante de escola pública dos setores populares.

O conteúdo se revela em diversos temas, tais como o da natureza humana, da violência, da educação, da família e do amor. Estes temas se enlaçam e nos encorajam a ter uma expectativa positiva sobre a educação como uma possibilidade de promover mudanças consentidas pelo próprio jovem. "Então, isso não é cortado na infância e... não é apresentado um amor, digamos assim, não é apresentada uma forma real do que realmente aconteceria se ela não quebrasse". Para o nosso interlocutor existe uma abertura cognitiva para se aprender, mediante o diálogo situacional e mais sincero do adulto.

Esta abertura cognitiva nos reporta ao texto de Bell Hooks (2004) "Escolarizando homens negros", que se apresenta como um manifesto para que possamos restaurar a ligação entre aprendizagem e libertação, e mais especificamente cuidar da educação dos homens negros no âmbito de perspectiva feminista. A autora se debruça sobre relatos autobiográficos de intelectuais negros, mostrando como as representações historicamente produzidas sobre homens negros podem ser reelaboradas por eles, tanto de forma negativa, quanto de forma positiva. Quando estas representações são vivenciadas no âmbito escolar, Bell Hooks assinala que o desempenho escolar pode ser interpretado de duas formas: como um resultado individual, cuja responsabilidade recai sobre suas incompetências para o aprendizado; como resultado de estruturas opressoras, tais como classismo, racismo, sexismo, homofobia ${ }^{5}$.

Desta forma, Bell Hooks acolhe a construção de escolas progressistas e não integralistas como uma alternativa encontrada pelos intelectuais negros estadunidenses que

\footnotetext{
${ }^{4}$ Ângelo é um estudante negro com 18 anos de idade e cursava o $3^{\circ}$ ano do ensino médio, em 2016.

${ }^{5}$ Neste texto bell hooks não discorre sobre a opressão homofóbica, ou melhor, sobre a LGBTfobia. Momento: diálogos em educação, E-ISSN 2316-3100, v. 26, n. 1, p. 191-210, jan./jun. 2017
} 
tiveram um compromisso com a educação voltada para superar a ideologia da supremacia branca. Em 1992, na nossa realidade baiana, o movimento negro construiu o Instituto Cultural Steve Biko, um curso pré-vestibular voltado para estudantes negros e negras ${ }^{6}$. Tais iniciativas são de fundamental importância, entretanto, elas não possuem de imediato, um alcance de larga escala para a população negra; mas servem de inspiração para políticas públicas educacionais para este segmento. Nesta senda, é preciso garantir meios que colaborem com a formação dos educadores/as para superar as estruturas opressoras constituídas pela moral majoritária, cujo conteúdo se mostra contrário a perspectivas e demandas das minorias.

Para nós, educadoras e pesquisadoras atuantes e/ou oriundas de escolas públicas baianas, é necessário investir fortemente na análise das lógicas de opressão do sexismo, do racismo e da desigualdade de classe e, para além das reflexões de Bell Hooks, nos ater também na lógica opressora da heteronormatividade. Em 1999, Suely Messeder examinou estas lógicas de opressão vivenciadas pelos jovens negros baianos em espaços de sociabilidade considerados de lazer pelos próprios jovens. Em 2017, Messeder e Elisete França analisaram estas opressões no âmbito escolar. Assim, como Bell Hooks, ambas as pesquisadoras investiram nas representações sobre masculinidades vivenciadas por homens negros. Como explorado em Messeder (2011), em seu artigo Navegando em busca do giro na heterossexualidade compulsória: a construção teórico-metodológica dos atos performativos masculinizados, o conceito de representação não está dissociado da prática; desta forma, desemboca no conceito teórico e metodológico de ato performativo, em que as ideias de três autores são articuladas - Connell (1994, 2013); Butler (2010); e Bourdieu (2007) -, tendo como resultado o acolhimento do ato performativo como a unidade de análise a ser observada no cotidiano dos jovens.

A observação da performatividade permite identificar a reiteração de normas que, anteriores aos jovens, são permanentemente reiteradas por eles e materializam aquilo que nomeiam. Desta forma, as normas reguladoras da classe, da raça e do sexo são performativas no sentido de reiterarem práticas já reguladas, materializando-se nos corpos. Com isto, não

\footnotetext{
${ }^{6}$ Ver a dissertação de mestrado intitulada A reafirmação da identidade étnica na família negra: a contribuição do trabalho educativo na Instituição Steve Biko, escrita por Iona Cristina Magalhães da Paixão Barata.

Momento: diálogos em educação, E-ISSN 2316-3100, v. 26, n. 1, p. 191-210, jan./jun. 2017
} 
podemos entendê-las como ato voluntário, mas sim como coibição, ainda que esta não se faça sentir como imposição e se apresente aparentemente como "natural".

Neste artigo escrito a seis mãos, procuramos compreender como os jovens negros reinterpretam as brincadeiras infantis na construção de suas masculinidades, mediante a reconstrução das narrativas destes rapazes, no âmbito de um grupo focal desenvolvido no contexto escolar soteropolitano. Não por acaso a brincadeira de luta entre as crianças foi reincidente no entabular da nossa conversa. Eles elegeram esta brincadeira como um tema privilegiado, entretanto, os diálogos ultrapassaram a fronteira das brincadeiras e outros temas também tomaram a cena.

$\mathrm{Na}$ literatura sobre masculinidades percebe-se a prevalência da ideia de um "homem verdadeiro". Quando o processo de racialização incide sobre este "homem verdadeiro", nos deparamos com a construção do estereótipo do homem negro, marcado pela supervalorização da virilidade, da força física, da violência, da pouca inteligência e da pobreza. $O$ corpo do homem negro é uma máquina de matar e morrer. Esta gramática da violência, operada para/pelas crianças, jovens e homens negros é registrada largamente no mapa da violência, nas mídias audiovisuais, jornais, programas de TV.

O Mapa da Violência 2016 - produzido pela Faculdade Latino-Americana de Ciências Sociais/FLACSO- (WAISELSZ, 2016), com foco na questão da violência por armas de fogo e suas variáveis, evidencia que aumentou o índice de violência contra a população negra no país. A taxa de homicídios de negros aumentou 9,9\% entre 2003 e 2014, passando de 24,9\% para 27,4\%. Pela pesquisa, a vitimização negra do país, que em 2003 era de 71,7\%, mais que duplicou: em 2014 alcançou 158,9\%, o que significa que morrem 2,6 vezes mais negros que brancos, por armas de fogo. Os homens representam 94,4\%, na média nacional, nos homicídios por arma de fogo; e a principal vítima é a juventude na faixa de 15 a 29 anos de idade. $^{7}$

No estado da Bahia, em especial, a violência contra jovens negros atingidos por armas de fogo teve um acréscimo de $123,7 \%$ pois, em 2004, foram mortos 8.100 deles e, em 2014 , o

\footnotetext{
${ }^{7}$ O Mapa da Violência compõe uma série de estudos desenvolvidos pelo pesquisador Julio Jacobo Waiselfisz, desde 1998, que tem como temática a violência. Informações retiradas do site http://www.seppir.gov.br/centralde-conteudos/noticias/2016/08-agosto/mapa-da-violencia-2016-morrem-2-6-vezes-mais-negros-que-brancosvitimados-por-arma-de-fogo.

Momento: diálogos em educação, E-ISSN 2316-3100, v. 26, n. 1, p. 191-210, jan./jun. 2017
} 
número subiu para 18.119 jovens. Com base no relatório do Mapa da Violência, podemos inferir que se trata de um verdadeiro genocídio.

Sobre as agressões presentes no contexto escolar é pertinente lembrar que as situações de violência têm aumentado nas escolas brasileiras. Conforme dados apresentados pelo relatório final do Programa Diagnóstico e Prevenção à Violência nas Escolas ${ }^{8}, 42 \%$ de jovens brasileiros sofrem agressões físicas ou verbais nas escolas; em Salvador, o índice apresentado foi de $39,7 \%$.

Essa contextualização sobre os dados estatísticos e manchetes veiculadas nas diversas mídias nos remete à narrativa de um dos nossos interlocutores:

Tirando os amigos que você conhece quando guri e entra pro mundo das drogas, vai pro caminho errado. Tipo, eu tinha uns 20 amigos e todo dia a gente ia pro campinho, aí hoje em dia eu não falo mais com ninguém porque a maioria tá no tráfico das drogas. Se eu falar eu posso até morrer. Então... foi mais isso mesmo" (Júnior, 2016) [sic]

Nessa narrativa ele fala da perda dos amigos de infância para o mundo das drogas e do medo de ser mais um a entrar na estatística da violência; por isso, opta por nem falar com aqueles que um dia já fizeram parte da sua vida. Antes de adentramos nas narrativas dos rapazes, detalharemos como se deu a nossa escolha metodológica e apresentaremos uma breve descrição do grupo focal e do perfil dos jovens participantes da pesquisa.

\section{SOBRE O GRUPO FOCAL}

O processo de pesquisa é fenômeno político que envolve operações sucessivas distintas e interdependentes, realizadas nos diálogos tecidos entre o/a pesquisador/a e os/as participantes da pesquisa, objetivando compreender sentidos, percepções e informações sobre um fenômeno de investigação, para melhor apreendê-lo. Miranda (2014) comenta que o Grupo Focal (GF) é uma técnica de discussão não diretiva em grupo, que reúne pessoas com alguma característica ou experiência comum para discussão de um tema ou área de interesse.

Gatti (2005) advoga que o grupo focal possibilita "fazer emergir uma multiplicidade de pontos de vistas e processos emocionais, pelo próprio contexto de interação criado, permitindo a captação de significados que, com outros meios, poderiam ser difíceis de

\footnotetext{
${ }^{8}$ Pesquisa realizada em 2015 pela FLACSO Brasil/OEI/MEC como parte integrante do Programa de Prevenção à Violência nas Escolas, sob a coordenação das pesquisadoras Miriam Abramovay e Mary Garcia Castro. A pesquisa foi realizada em sete capitais (Belém, São Luís, Fortaleza, Maceió, Salvador, Belo Horizonte e Vitória). 9 Júnior é um estudante do $3^{\circ}$ ano do ensino médio, tem 20 anos de idade, cor parda, segundo a classificação do IBGE.

Momento: diálogos em educação, E-ISSN 2316-3100, v. 26, n. 1, p. 191-210, jan./jun. 2017
} 
manifestar" (p. 09). Para nós, o grupo focal constituiu-se como uma técnica facilitadora para que os rapazes expressassem seus conflitos e finidades, exercitando a dialogicidade, bem como externassem suas crenças, valores, preconceitos. É um instrumento que permite a compreensão dos processos de construção da realidade, afirma Gatti (2005), e Macedo (2006) completa comentando que, esse recurso entra de forma consistente na prática da apreensão das realidades múltiplas, e como instrumento de pesquisa eminentemente grupal é muito relevante para as pesquisas em educação.

O grupo focal de que trata este artigo foi realizado com oito estudantes do $3^{\circ}$ ano do Ensino Médio, numa escola situada no bairro que, segundo a mídia, é o mais violento da cidade de Salvador. Iniciamos o nosso diálogo com apresentação de cada participante do grupo informando seu nome e idade e, em seguida, a pesquisadora jogou o tema na roda: "as brincadeiras infantis". Os olhares se entrecruzaram, quando Cléber tomou coragem e começou a falar e, daí em diante, todos começaram a falar, num clima mais descontraído, com uma duração de mais ou menos duas horas. Vamos conhecer um pouco destes rapazes:

\section{PERFIL DOS GAROTOS}

Para alguns autores a seleção dos participantes do grupo focal deve ter uma homogeneidade, a qual ocorre em função do grupo social a ser estudado, devendo envolver pessoas de diferentes faixas etárias, gênero e classe social. No caso especifico do nosso público, escolhemos apenas jovens do sexo masculino e na faixa etária entre 18 e 20 anos de idade; no que se refere à cor/raça, só participaram estudantes pardos e pretos, em pesquisas quantitativas constata-se que a maioria dos jovens estudantes das escolas públicas baianas são pardos e pretos.

Gilson é um estudante negro, de 18 anos de idade, com cerca de 1,70m, cabelos pretos cortados à altura da nuca, um pouco mais alto na região frontal, sem cachos e tem também algumas características dos povos indígenas; é magro, tem olhos pretos e sua prática sexual é com mulheres.

Cléber tem 20 anos, é negro, com cerca 1,65m de altura, corpo que foge dos padrões estéticos estipulados e normatizados pela cultura da magreza; fala muito, têm cabelos pretos cortados na altura da nuca, olhos pretos e pratica sexo com mulheres. 
Júnior é um estudante de 20 anos de idade, do $3^{\circ}$ ano do ensino médio e, segundo a classificação do IBGE, tem cor parda, usa um fino bigode, cabelos castanho-escuros cortados ao alto da nuca; tem estatura mediana, corpo magro e, durante a conversa no grupo, optou por ficar sentado bem largado na cadeira, com as pernas bem esticadas em direção ao centro do semicírculo; ele pratica sexo com mulheres.

Waldemir é um estudante que se identifica como pardo, possui olhos castanho-claros e cabelos também; tem 18 anos, cerca de 1,70m, é muito observador. Durante os momentos com o grupo, optou por ficar mais calado e não quis participar da entrevista individual. Possui um corpo magro e sua prática sexual é com mulheres.

César é pardo, tem 18 anos, olhos castanho-escuros, cabelo preto longo até a altura do pescoço, escovados; usa brincos, óculos, mede cerca de $1,65 \mathrm{~m}$ e sua prática sexual é com homens.

Ângelo é negro, tem cerca 1,70m de altura, 18 anos de idade, cabelos pretos cortados na altura do pescoço; é magro, com um corpo bem definido, atendendo aos padrões estabelecidos como belos pela cultura da magreza, sua prática sexual é com mulheres.

Ronald é moreno, cabelos castanho-claros com corte estilo militar, tem 18 anos com cerca de 1,70m de altura tem um corpo forte com os músculos bem definidos como se praticasse musculação constantemente e prática sexual com mulheres.

Fábio é magro, pardo, cabelos castanhos, olhos castanho-escuros; é alto, com cerca de $1,70 \mathrm{~m}$, cabelo cortado baixinho e sua prática sexual é com mulheres. 


\section{AS BRINCADEIRAS DE MENINO}

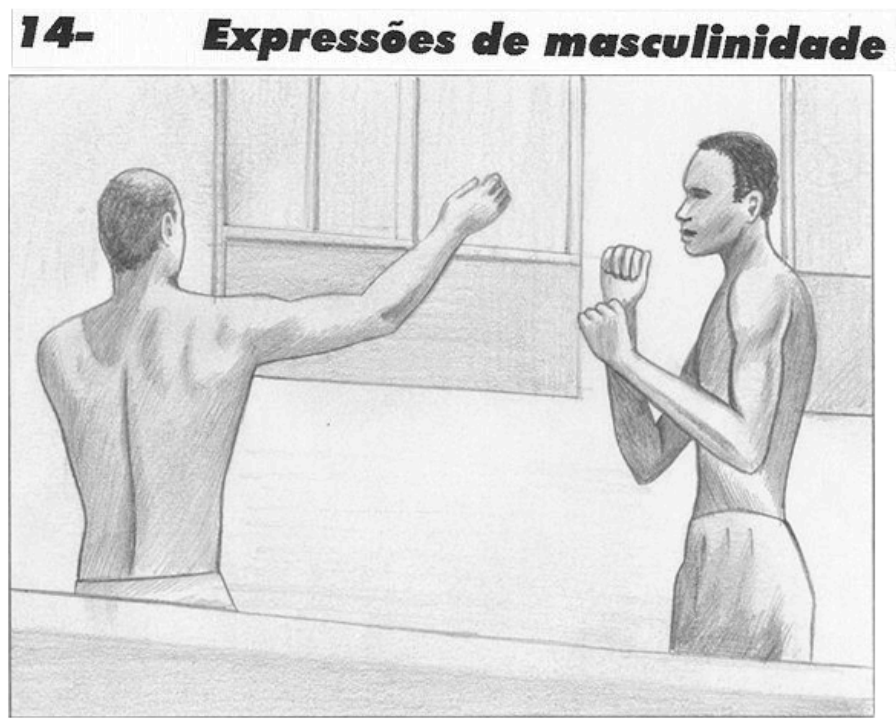

\section{A brineadeira de lufa}

Figura 1. Imagem de arquivo pessoal ${ }^{10}$

Nesta seção iremos apresentar como os rapazes vão construindo os seus discursos, tendo como tema as brincadeiras na infância. A figura ilustra que a brincadeira de luta que reside na memoria da infância persiste na adolescência destes jovens. Vejamos quais as principais brincadeiras citadas por eles.

\section{SOBRE OS TIPOS DE BRINCADEIRAS}

Cléber: Esconde-esconde, pega-pega, rasteira, futebol. Todo mundo praticamente fez a mesma coisa.

Para Cléber, a brincadeira é uma prática generalizada entre eles. Nesta citação vimos que existem brincadeiras que podem ser consideradas exclusivamente de meninos; mais adiante, eles nos aclararão sobre esta divisão sexual das brincadeiras. Ainda sobre os tipos de brincadeiras:

Ronald: Todo mundo praticamente fez a mesma coisa. Handebol também na escola... Brigando na rua. Além do acréscimo de mais dois tipos, em que ele ratifica a ideia generalizada de que todos "fazem a mesma coisa":

\footnotetext{
10 A imagem integra o livro MESSEDER, Suely Aldir. Ser ou não ser: uma questão para "pegar" a masculinidade- um estudo sobre a performatividade pública da masculinidade de rapazes negros na cidade do Salvador. Salvador: EdUNEB, 2009.

Momento: diálogos em educação, E-ISSN 2316-3100, v. 26, n. 1, p. 191-210, jan./jun. 2017
} 

a) Esconde-esconde;
b) pega-pega;
c) rasteira;
d) futebol;
e) handebol
f) a luta.

Estas brincadeiras nos remetem ao texto "Brincadeiras de menino, brincadeiras de menina", cujo conteúdo versa sobre uma pesquisa realizada com:

\begin{abstract}
As crianças de classe média alta, que frequentavam escolas particulares caras, e moravam em bairros residenciais; e crianças de classe baixa, que frequentavam creches e escolas públicas, e moravam em favelas ou bairros pobres de periferia. Em cada caso, foram pesquisadas 15 crianças de cada sexo em cada faixa etária $(5,8$ e 10 anos) (CARVALHO; BERALDO; SANTOS; ORTEGA, 1993)
\end{abstract}

Das brincadeiras elencadas nos dois contextos da pesquisa vimos que as mais citadas são a Lutinha e o Futebol, ambas apresentam estereotipia fortemente masculina. Curiosamente, quando um dos rapazes citou "brigando na rua", todo o grupo se animou a entrar na conversa:

Valdemir: Brincar de luta...

Cléber: Luta? Luta é até hoje!

Ronald: É. Você começa a bater no cara só por brincadeira...

Valdemir: Não, mas tipo, na época que você brincava não era aquele chute, aquele... (estudantes ao fundo: é, é...)

Valdemir: É, não, mas tipo assim! Aquela época era só brincadeira; não batia pra dominar (Risos), era só briga de ombro, tá ligado?!

Cléber: Bater no ombro. Aquela parte de quê um olha o outro "Qual foi? Qual foi?" (Risos ao fundo).

As falas não são suficientemente explicativas para dar conta desta brincadeira de luta. Os rostos tornam-se bravos, as vozes mais firmes e o bater do ombro repetido constantemente, como se fora encostar-se ao adversário. A explicação sobre a brincadeira de luta prossegue com mais ânimo:

Ronald: É, aquele, batia pra dominar (Risos). Hoje em dia é aquela briga de ombro, tá ligado (Risos)?"

Para além desta luta de rua, a conversa é entrecortada pela seguinte fala: 
Ronald: O outro Lucas deve ter alguma coisa na nossa infância que vocês não teve; eu acho, né? Quem já assistiu, aqui, Dragon Ball, Naruto? (Risos)

Cléber: Você é maluco, é? (Risos)

Fábio: Assistia desenho aqui, pô, todo mundo aqui fazia a mesma coisa.

Este breve diálogo nos leva para os desenhos animados que tratam de violência, cujos conteúdos ficaram retidos nas memórias destes rapazes. No artigo "Cenas (im)próprias para crianças", Rocha (2012) nos mostra como meninos significam o anime japonês Dragonball Z, tendo como eixos temáticos :"lutar-agredir" e "cuidar-proteger", a partir das relações entre três personagens - Goku, Gohan e Piccolo (em suas posições de pai, filho/discípulo e mestre, respectivamente). Talvez inspirado pela citação do filme, um dos rapazes nos reporta ao seu pai:

Ronald: Eu acho que isso aí já vem... Tipo, desde guri, desde pequeno. Ou então... meu pai mesmo, desde pequeno a gente brincava de luta, meu pai treinava Jiu Jitsu. Mas não é o caso, eu acho que, desde o tempo assim... Às vezes é genético, assim, todo mundo brinca.

$\mathrm{Na}$ sua narrativa Ronald nos convoca a pensar sobre dois eixos: A) a luta como um processo de aprendizagem, um adulto como responsável; B) a natureza humana. Se, por um lado, observamos que esta violência é naturalizada entre eles, por outro, nos surpreende a desconstrução elaborada, ainda por eles, da suposta natureza masculina agressiva. Já nos dois eixos citados pela autora, o cuidar-proteger pode figurar na interpretação elaborada pelas crianças no anime Japonês, quando os/as educadores/as deixam de atuar sobre a regra da moralidade majoritária e se permitem escutar as próprias crianças.

Ainda, no desenrolar do grupo focal, eles revelam com quem podem brincar de luta. Vejamos:

\section{EM QUEM SE PODE BATER?}

Fábio: A gente brinca de bater... falem aí , sejam verdadeiros cada um aqui. Só brinca de bater com quem você sabe que você "guenta", que é mais fraco que você.

Cléber: Realmente

Fábio: A gente brinca de bater, pra assim, mostrar que é mais forte que a pessoa. Eu tenho pra mim que é por causa disso aí. Pra demonstrar nossa masculinidade. E também quando vê que outra pessoa mais forte vai cair pra dentro (Risos). Nesse momento ele bate uma mão fechada contra outra aberta, como se fosse esmurrar alguém.

Valdemir: Primeiro começa batendo nos mais fracos... pra aprender, ir aprendendo (Risos)

Cléber: Pra depois bater em todo mundo (Risos)

Momento: diálogos em educação, E-ISSN 2316-3100, v. 26, n. 1, p. 191-210, jan./jun. 2017 
Estas narrativas nos mostram as estratégias de quem pode bater? Ela nos reporta á cena do filme Moonlight: Sob a Luz do Luar (JENKINS, 2016). Numa escola do subúrbio estadunidense, um estudante negro e franzino com jeito de "bicha" sofre bullying dos seus colegas de classe. Em uma das cenas, talvez a mais forte, vários rapazes o cercam e esses mesmos obrigam um dos seus integrantes a surrar o colega afeminado. Esse episódio ocorre no horário da saída da escola; o que para nós é significativo, pois a violência contra as crianças afeminadas e "rapazes bichas" são frequentes nas escolas públicas. O que é ratificado também pelo trabalho realizado por França (2012) sobre as sexualidades na escola e na formação docente. No trabalho da autora foi observado por meio das narrativas dos/as docentes e pelas observações que a escola vivencia a tensão de publicizar, ao mesmo tempo, controlar as sexualidades, visto que ela se fecha em um arcabouço para tornar normal a heterossexualidade e vigiar/coibir as sexualidades dissidentes. Assim, as violências físicas e morais contra os/as jovens considerados "bichas" são uma constante.

Tais reincidências de violência provocaram a formulação de políticas públicas necessárias que afetaram diretamente o currículo, e vários cursos para formação de educadores/as foram realizados, sobretudo, pela Secretaria de Educação Continuada, Alfabetização, Diversidade e Inclusão (SECADI) ${ }^{11}$. Esta história será rapidamente contada em nota de rodapé, não porque não seja merecedora de destaque. $\mathrm{O}$ argumento para não dar continuidade a esta história é simples, uma vez que neste espaço nos interessa focar nas vivências dos jovens rapazes. Depois de apresentar a violência dos rapazes contra rapazes considerados mais frágeis, vejamos como eles se relacionam com as meninas:

\section{E QUAIS AS MENINAS QUE PARTICIPAM DESTAS BRINCADEIRAS?}

Fábio: ah! Tem umas meninas que brinca... e batem . (Risos)

Ronald: Tipo tem umas meninas que batem. Tá ligado? Eu não posso bater, então elas me batem, fico tipo quieto e apanho. Ou então corro. Tá ligado?

\footnotetext{
${ }^{11}$ A SECADI tinha como função articular com os sistemas estaduais e municipais de ensino a implementação de políticas educacionais voltadas para atender as áreas de alfabetização e educação de jovens e adultos, educação ambiental, educação em direitos humanos, educação especial, do campo, escolar indígena, quilombola, educação para as relações étnico-raciais e para questões de gênero e sexualidade. Informações disponíveis em http://portal.mec.gov.br/component/content/index.php?option $=$ com_content\&view=buscageral\&Itemid $=30188 \&$ params $\% 5$ Bsearch_relevance $\% 5 \mathrm{D}=$ direitos+humanos\&params $\% 5 \mathrm{Bde} \% 5 \mathrm{D}=\&$ params $\% 5 \mathrm{Bate} \% 5 \mathrm{D}=\&$ params $\% 5$ Bcatid $\% 5 \mathrm{D}=\&$ params $\% 5 B$ search_method $\% 5 \mathrm{D}=$ all\&params\%5Bord $\% 5 \mathrm{D}=\mathrm{pr}>$ Acesso 16 de abr de 2017.
}

Momento: diálogos em educação, E-ISSN 2316-3100, v. 26, n. 1, p. 191-210, jan./jun. 2017 
Primeiro, somos levadas a acreditar que as brincadeiras de bater não ocorrem com as meninas, porque embora elas possam bater, elas não levam a "sério" tal brincadeira, e o ato de bater não passa de uma ação sem reação. Por sua vez, eles também se recusam a dar continuidade. Entretanto, na continuidade da conversa, eles tecem comentários sobre as meninas que gostam de bater a sério:

Cléber: Ah! Tem aquelas "muleque macho", que gostam de bater.

Elisete: Umas meninas o quê?

Cléber: Muleque macho. Que gosta de bater nos outros.

Mais adiante eles são interpelados para clarear o significado de muleque macho:

Fábio: Sai batendo, tipo pra arregaçar.

Cléber: Elas saem batendo, tipo botou a base e vem com a mão e batem para valer. (nesse momento o Cléber gesticula e movimenta o corpo para frente com as mãos fechadas, punhos firmes, como se fosse agredir com um murro outra pessoa).

Fábio: Isso que você falou é a menina mais fraca. Tem umas que nem avisa, vem de lá e você já toma no "ovo". (nesse momento ele bate com uma das mãos fechada sobre a outra aberta, encenando um murro sobre os testículos, bem como modifica a face, demonstrando sentir dor).

Ainda, para esclarecer sobre a representação de moleque macho, Elisete insiste:

Elisete: E essas meninas, que você disse que é "muleque macho", tem alguma característica que vocês acham que ela... (não foi possível completar o questionamento, imediatamente Fabio interrompeu, respondendo).

Fábio: elas são agressivas, agressivas...

Elisete: Agressiva, só isso? Tem mais alguma coisa?

Cléber: agressivas e gostam de bater

Fábio: Não, o corpo... É, tem umas que são bonitas, tem umas que são feias. Mas a maioria mesmo é mais bonita.

Ronald: Mas a muleque macho desenvolve atividades, que normalmente quem faz é os meninos, né? Vai jogar bola... Isso é coisa de criança né, mas quando cresce já vira outra coisa... já vira outros apelidos, né...[sic]

Os rapazes não escapam da coerência imputada ao sistema de gênero, da relação direita do sexo ao gênero, do gênero ao desejo sexual. Desta forma, eles determinam o futuro destas meninas que se apresentam como recíprocas em suas brincadeiras. Vejamos o que Ronald diz:

Ronald: Lésbica, roçona, essas coisas. (Risos) 
Ronald denomina as meninas que brincam com brincadeiras de brigar/lutar como "lésbicas" e "roçonas", visto que as brincadeiras são imaginadas como atividades essenciais para o processo de constituição identitária dos sujeitos sociais. São atividades engendradas, onde os papéis de gênero estão sempre presentes, sendo validadas ou não pelos outros sociais. Ainda no diálogo, o grupo tenta aprofundar sobre o que reconhece nas meninas que eles chamam pejorativamente de moleque macho:

Fábio: Essas "muleque macho" são agressivas em dois aspectos né, em dois lugares (Risos). $\mathrm{Na}$ vida alheia e na particular. Vida alheia é com o pessoal, e particular é com as amigas delas mesmo. [sic]

Elisete: E na vida alheia, elas são agressivas como?

Fábio: Com os meninos por causa que sabem que homem não pode bater em mulher, e então sai caindo batendo nos homens. [sic]

No diálogo supracitado observamos que Fábio faz uma distinção entre as meninas que ele denomina de moleque macho, a partir da agressividade, comentando que essas meninas são mais violentas, uma vez que elas são conscientes de que os meninos não podem bater nelas. Nessa colocação, os garotos citam a Lei Maria da Penha como um elemento protetor para as mulheres, e Ângelo imediatamente comenta sobre a abrangência da Lei.

Ângelo: Na verdade a Lei Maria da Penha cobre também contra mulher

Ronald: Lei Maria da Penha é pra qualquer agressão familiar e domiciliar né...

Ângelo: E além de agressão física...

Ângelo e Ronald dialogam sobre a Lei Maria da Penha, o que é de extrema relevância para o momento em que vivemos, com alto índice de violência contra a mulher, em especial no estado da Bahia onde, só nos três primeiros meses de 2017, foram registrados 2.538 casos nas Delegacias Especiais de Atendimento à Mulher (DEAM). E, segundo manchete do jornal Correio da Bahia $^{12}$, a cada 56 minutos uma mulher é vítima de violência na capital do estado.

Interessante é a ponderação feita por Ronald, quando chama atenção para as formas de agressão "familiar e domiciliar", tentando inferir que essa Lei não atende só mulheres, mas qualquer tipo de violência domiciliar. È pertinente informar que a violência doméstica se refere a qualquer tipo de violência contra um membro do núcleo familiar. E a Lei

\footnotetext{
${ }^{12}$ Ver manchete no site $<\mathrm{http}$ ///www.correio24horas.com.br/detalhe/salvador/noticia/a-cada-56-minutos-umamulher-e-vitima-de-violencia-em-salvador/?cHash=b06a251daee9f4bf32b2930739d7f1f3> acesso em 21 de abr. de 2017.

Momento: diálogos em educação, E-ISSN 2316-3100, v. 26, n. 1, p. 191-210, jan./jun. 2017
} 
11.340/2006, trata especificamente da violência contra a mulher, e traz um conjunto de ações que devem ser articuladas entre os entes federados de forma a promover políticas que busquem garantir os direitos humanos das mulheres.

Ângelo amplia a compreensão, informando que a Lei não atende apenas a violência física. Depois da breve digressão sobre a Lei Maria da Penha, um deles se lembra de outra brincadeira com as meninas:

Cléber: Brincar de papai e mamãe...Quando você é criança você brinca, você ainda brinca com algumas meninas. "Não, bora brincar de papai e mamãe". A menina senta no seu colo (Risos) (falando pra outro estudante) Você nunca fez isso não? Você nunca fez isso? Você não teve infância não, na moral velho... "Aí eu sou o papai e você é a mamãe. Tá na hora de dormir, pronto". Dorme na mesma cama. "Tá na hora de fazer filho", pronto faz, cabô, só isso.

Elisete: E tem o ato? $\mathrm{O}$ ato de como se estivesse dormindo? (Risos)

Cléber: Eu era muito inocente, tirei meu bv com 12 anos...

Elisete: O seu o quê?

Cléber: Meu bv. (Risos)

Cléber evidencia, na sua narrativa, a sua percepção sobre os papéis de gênero, tendo como ponto de partida a relação estabelecida entre casais heterossexuais, bem como o patriarcado nas relações matrimoniais heterossexuais.

Interessante é como César desconstrói a naturalização de ser homem e ser mulher. Vejamos o que diz com relação ao diálogo tecido sobre as brincadeiras da infância, em especial sobre as brincadeiras de brigas/lutas:

César: É porque, na verdade, a sociedade, ela é machista. Todo mundo nasce e acha que porque você é homem você tem que brincar de bater, porque se você não brincar de bater você vai ser a menininha, ou o viadinho. E a mulher, ela é, simplesmente, rotulada como muleque macho porque ela age como homem, mas não, ela age como qualquer outra pessoa iria agir. Não existe essa coisa de que você é viadinho porque você faz isso, você é muleque macho porque você faz isso. Todo mundo, todo ser humano tem o mesmo comportamento, independente do seu gênero.

Baseados em uma visão dicotômica acerca dos papéis de gênero são construídos preconceitos que reverberam nos modos de ser e conviver dos sujeitos sociais, bem como nos brinquedos e brincadeiras de infância. E César apresenta para o grupo uma reflexão sobre essa naturalidade. Bell Hooks (2013) comenta que muitos homens jovens negros estadunidenses enfrentam o desafio de ousar a criticar o patriarcado e o sexismo. E César faz essa Momento: diálogos em educação, E-ISSN 2316-3100, v. 26, n. 1, p. 191-210, jan./jun. 2017 
transgressão trazendo para o debate as questões dos estereótipos e da determinação dos papéis de gênero. Ele continua comentando as brincadeiras:

César: Sobre brincadeira de bater, eu particularmente não vivi nessa parte aí, sobre brincar de bater, eu nunca gostei de brincar de bater porque eu acho que todo mundo sente dor, tanto homem quanto mulher, todo mundo tem tudo que todo mundo tem e eu nunca brinquei de bater porque eu não achava isso certo. E nunca achei que se um menino não brincasse de bater ele seria viado por conta disso, tanto que minha infância nunca foi baseada em Dragon Ball Z e nada disso, era sempre eu e meu primo, não vou mentir, eu assistia muito Barbie, eu e meu primo, e hoje ele é hetero e eu sou gay. Mas o assistir à Barbie não influenciou ele ser quem ele é hoje e nem eu, entendeu? Então, a sociedade, ela infelizmente é machista até hoje, ela tenta rotular e dizer que a mulher é isso e aquilo e homem é mais do que todo mundo.

Sobre os desenhos animados, Rael (2008), em seu artigo sobre gênero e sexualidade nos desenhos da Disney, comenta que esses desenhos se constituem em artefatos pedagógicos culturais que apresentam heroínas/heróis, vilãs/vilões, bem como representações de papéis de gênero interseccionados com raça e classe, que são veiculados nas diversas instâncias formativas veiculando e reiterando as representações de gênero.

E esse papel formativo foi expresso no diálogo tecido por nossos interlocutores durante o GF,quando César, mais uma vez, transgride o naturalizado pelo grupo e fala da igualdade entre homens e mulheres, salientando que o fato de brincar ou não de bater não influencia a construção das masculinidades e feminilidades, bem como o fato de gostar e assistir determinados desenhos animados.

O diálogo prossegue com César problematizando a norma estabelecida culturalmente para a linearidade de sexo/gênero associado às brincadeiras e animes infantis. Ao terminar de falar, César é interpelado por Fábio, que questiona: "Você nunca assistiu Dragon Ball Z? (Risos)" imediatamente Cléber interrompe pontuando: "O cara fez um discurso do 'caralho' e nunca assistiu Dragon Ball Z. (Risos) Tem hora que o cara fala, fala, fala, e, quando chega na hora que você gosta, você esquece tudo (Risos)". Cléber parece ter sido tocado pelo discurso de César sobre a naturalização e normatização dos papéis de gênero presentes na nossa sociedade, bem como outros garotos, pois após a narrativa de César, aconteceu um silêncio de cerca de 30 segundos, alguns olhando para o chão e outros para o alto. Foi um momento que nos levou também a pensar sobre a educação que é oferecida nas nossas escolas que, geralmente, não propiciam uma discussão sobre temas que mais impactam a vidas dessas/es jovens. Nesse sentido, Hooks (2013) diz que quando nós educadoras/es permitimos que a 
nossa pedagogia seja implicada e transformada na multiculturalidade e diferenças do mundo poderemos dar as/aos nossas (os) estudantes uma educação que elas/es desejam, de forma a fomentar a autonomia e transformar a consciência dos sujeitos sociais. Fábio continua questionando a infância e retoma a discussão sobre os desenhos animados.

Fábio: Você não teve infância, velho? (Risos).

César: Eu tive uma infância maravilhosa.

Fábio: Diga pra mim, qual foi o desenho que você assistiu?

César olha atentamente para Fábio e balança a cabeça respondendo negativamente ao questionamento do colega e, em seguida, fala: Barbie.

Fábio: Só Barbie? Nem Bob Esponja? (Risos) Tem que ter pelo menos um... Quer ver um desenho que todo mundo já assistiu? Você nunca assistiu Power Rangers? Vai dizer...

César: Eu era a rosa. A Power Ranger rosa (Risos).

Fábio ainda permanece na lógica da linearidade sexo/gênero, bem como na homogeneidade das ações infantis, e insiste que César tenha ao menos assistido Bob Espoja, um desenho animado criado em 1999 pelo biólogo Stephen Hillemburg e que, segundo pesquisa realizada por Andrade e Oliveira (2010) sobre a preferência de estudantes da faixa etária de 8 a 12 anos, de escolas públicas da região metropolitana do Recife, acerca dos desenhos animados e personagens, apontou o anime Bob Esponja Calça Quadrada como o mais visto por meninas e o segundo mais assistido por meninos, pois o primeiro foi Dragon Ball. Esse desenho citado por Fábio seria, na percepção dele, aceitável para ser assistido por meninos e meninas.

Ainda na linha da desconstrução dos estereótipos, César diz gostar de um outro desenho, a Barbie, boneca criada em 1959 pela empresária Ruth Handler que reflete a cultura eurocêntrica, representando a mulher branca e rica. E Power Ranger Rosa que apresenta a visão de um super-herói que foge ao padrão estabelecido pela heteronormatividade. Enfim, observa-se que as representações de gênero têm função relevante no constituir-se dos garotos, bem como marcam e reforçam uma cultura androcêntrica e heterossexista.

\section{CONSIDERAÇÕES}

Ao longo destas reflexões sobre atos performativos de rapazes negros estudantes da escola pública, tendo como foco as brincadeiras infantis; foi possível identificar que a 
brincadeira de luta ou a briga é mais praticada por eles, embora tivessem elencado o pegapega, futebol, rasteira, handebol, esconde-esconde, os desenhos animados animes, papai e mamãe.

Vimos que suas interpretações sobre a luta nos reportam a outras dimensões que nos colocam na ambiguidade entre o natural e cultural (aprendizado), daí a possibilidade de apostar nas zonas dos interstícios, enfrentando a moralidade da maioria, tendo como conteúdo a ser trabalhado as diversidades das próprias vivências.

As estruturas de opressão de classe, raça, gênero, práticas sexuais se constituem na materialidade dos seus corpos; representações idealizadas moralizantes são utópicas, distantes das suas interações, aliás, são elas que martirizam e promovem a violência que incide sobre seus corpos. Daí, eles apelam para o discurso do amor, nestas zonas dinamitizadas em que vivem, e uma pergunta nos interpela: Nós, educadores/as baianos/as, o que podemos fazer pelos nossos jovens negros, cujos corpos são marcados para matar e morrer?

\section{REFERÊNCIAS}

ABRAMOVAY, M. Coord. Juventudes na escola, sentidos e buscas: Por que frequentam? / Miriam Abramovay, Mary Garcia Castro, Júlio Jacobo Waiselfisz. Brasília-DF: Flacso Brasil, OEI, MEC, 2015.

ANDRADE, A. C. de. ; OLIVEIRA, L. M. P. Z. de. As crianças da Rede Pública de Ensino e os Desenhos Animados. XII Congresso de Ciências da Comunicação na Região Nordeste. Campina Grande, p. 1-15, 2010.

BOURDIEU. P. A dominação masculina. Tradução de Maria Helena Kühner. 5.ed. Rio de Janeiro: Bertrand Brasil, 2007.

BUTLER, J. Problemas de Gênero: Feminismo e subversão da identidade. Rio de Janeiro: Civilização Brasileira, 2010.

CARVALHO, A.; BERALDO, K.; SANTOS, F.; ORTEGA, R. Brincadeiras de menino, brincadeiras de menina. Psicol. cienc. prof. Vol.13 no.1-4 Brasília, 1993.

CONNELL. R. W. Políticas da Masculinidade. Educação e Realidade 20 (2) jul/dez 1995. pp. 185-206.

; MESSERSCHMIDT, J. W. Masculinidade hegemônica: repensando o conceito. Estudos Feministas, Florianópolis, v. 21, n. 1, p. 241-282, maio 2013. ISSN 0104026X. Disponível em: $<$ https://periodicos.ufsc.br/index.php/ref/article/view/S0104026X2013000100014>. Acesso em: 01 abr. 2016.

FRANÇA. E. S. da C. Saindo do "armário" quantas portas se abrem/fecham?: as sexualidades na escola e na formação docente, 2011. 120f. Dissertação (Mestrado em Crítica Cultural). Universidade do Estado da Bahia, Campus II Alagoinhas, 2011.

Momento: diálogos em educação, E-ISSN 2316-3100, v. 26, n. 1, p. 191-210, jan./jun. 2017 
GATTI, B. A. Grupo focal na pesquisa em ciências sociais e humanas. Brasília: Líber Livro Editora, 2005.

HOOKS, B. Ensinando a transgredir: a educação como prática de liberdade. Tradução de Marcelo Brandão Cipolla. São Paulo: Editor WMF Martins Fontes, 2013.

. Escolarizando homens negros. In: Estudos Feministas, Florianópolis, 23(3): 677689, setembro-dezembro/2015.

MACEDO. R S. Etnopesquisa crítica, Etnopesquisa-formação. Brasília: Líber Livro Editora, 2006.

MESSEDER, S. A. Navegando em busca do giro na heterossexualidade compulsória: a construção teórico-metodológica dos atos performativos masculinizados. In: Cosme Batista dos Santos; Paulo César Garcia; Roberto Seidel. (Org.). Critica cultural e educação básica: diagnósticos, proposições e novos agenciamentos. São Paulo: Edunesp, 2011.

MESSEDER, Suely Aldir. Ser ou não ser: uma questão para "pegar" a masculinidade - um estudo sobre a performatividade pública da masculinidade de rapazes negros na cidade do Salvador. Salvador: EdUNEB, 2009.

MIRANDA, A. C. de S. Gênero/Sexo/Sexualidade: representações e práticas elaboradas por professoras/es da educação infantil na rede municipal de ensino em Salvador, 166 f. 2014. Dissertação (Mestrado) Universidade Federal da Bahia. Faculdade de Filosofia e Ciências Humanas, 2014.

Moonlight: sob a luz do luar. Direção: Barris Jenkins, Produção: Adele Romanski, Dede Gardner, Jeremy Kleiner. Estados Unidos da América: Plan B Entertainment \& Pastel Productions, 2016.

RAEL. C. C. Gênero e sexualidade nos desenhos da Disney. In: LOURO. Guacira Lopes, FELIPE, J.; GOELLNER. S. (Org). Corpo, gênero e sexualidade: um debate contemporâneo na educação. $4^{\mathrm{a}}$ Ed. Petrópolis, RJ: Vozes, 2008.

ROCHA, M. da. Cenas (im)próprias para crianças? Cad. Cedes, Campinas, vol. 32, n. 86, p. 97-115, jan.-abr. 2012

WAISELSZ, J. J. Mapa da violência 2016: homicídios de armas de fogo no Brasil. Rio de Janeiro: FLACSO, 2016.

\section{Sites}

http://www.seppir.gov.br/central-de-conteudos/noticias/2016/08-agosto/mapa-da-violencia2016-morrem-2-6-vezes-mais-negros-que-brancos-vitimados-por-arma-de-fogo

http://g1.globo.com/bahia/noticia/2014/11/homicidio-de-jovens-negros-cresce-cada-ano-naba-impunidade-permite.html

http://apublica.org/2013/07/jovens-negros-na-mira-de-grupos-de-exterminio-na-bahia/

http://brasil.elpais.com/brasil/2015/07/25/politica/1437834347 077854.html

http://www.seppir.gov.br/central-de-conteudos/noticias/2016/08-agosto/mapa-da-violencia2016-morrem-2-6-vezes-mais-negros-que-brancos-vitimados-por-arma-de-fogo

Momento: diálogos em educação, E-ISSN 2316-3100, v. 26, n. 1, p. 191-210, jan./jun. 2017 
http://www.correio24horas.com.br/detalhe/salvador/noticia/salvador-tem-dez-denuncias-pordia-de-agressao-contra-criancas/?cHash $=54819$ ecca6da723bd2e3dd32d4963d09

O Vanguardista - $\quad \mathrm{iG} @$ http://ovanguardista.ig.com.br/velha-infancia/2017-0126/brincadeiras-crinaca-origem.html

http://www.correio24horas.com.br/detalhe/salvador/noticia/a-cada-56-minutos-uma-mulher-evitima-de-violencia-em-salvador/?cHash=b06a251daee9f4bf32b2930739d7f1f3 * acesso em 21 de abr de 2017. 